\title{
JAVIER GOROSQUIETA
}

\section{Evolución Económica y Comercio Exterior, 1969-1970}

En reciente informe del Banco Atlántico sobre la evolución de la economía española en 1969 se nos dice que "la estabilidad externa se ha sacri. ficado en aras de un menor crecimiento de unos precios congelados". El mismo informe declara, por otra parte, que el crecimiento del producto interior bruto al coste de los factores se ha cifrado en un 78 por 100 superior a la tasa del 5,5 por 100 , que había sido prevista en el Plan de Desarrollo.

Crecimiento en la estabilidad interna de los precios. Tal ha sido la tónica esencial de 1960. El indice del coste de la vida efectivamente subió durante el año sólo en un 3,5 por 100 .

El crédito bancario contribuyó a animar la conyuntura: durante 1969 ha sido superior al aumento de los depósitos, y éstos, en términos absolutos, se mueven en torno al billón de pesetas. La euforia económica se manifestó en la Bolsa: 1960 ha sido el mejor año bursátil en la década de los 60.

Desearíamos para 1970 la repetición del "menú del desarrollo" de 1969: alto crecimiento de la renta nacional en la casi práctica estabilización del coste de la vida. El actual recalentamiento de los precios y cierta contracción del crédito bancario nos auguran, sin embargo, que tal propósito no va a ser fắcil de conseguir.

Pero, como deciamos al principio, el coste de este sucutento menú ha estado en la estabilidad externa, en el comercio exterior. Analizmos a continuación algún rasgo esencial de st problemática.

\section{Comercio exterior}

El II Plan de Desarrollo creó las denominadas señales de alerta, destinadas a llamer la atención sobre las desviaciones respecto a lo programado más altá de un prudente limite de tolerancia. 


\section{J. GOPOSQUIETA}

Hay dos, de las seis senales de alerta creadas, que tienen relachón directa con el comercio exterior.

La primera es el porcentaje de cobertura de las exportaciones sobre las importaciones: la señal funciona cuando el porcentaje medio de seis meses des. ciende en cuatro puntos del correspondiente a los mismos meses del año anterior.

La segunda es la variación de las reservas de divisas: entra en funcio namiento esta señal de alerta cuando la pérdida de reservas a lo largo de los ultimos doce meses es superior al 10 por 100 del nivel de reservas existentes al comienzo de dicho periodo.

Durante 1969 ha funcionado esta útima señal de alerta: la reserva de di visas. De enero a diciembre las reservas descendieron no en un 10, sino en un 23,9 por 100 . En diciembre de 1968 disponianos de 1.095 millones de dó lares en reservas de divisas; en noviembre de 1966, solamente 850 millones de dólares.

El indice de cobertura de exportaciones sobre importaciones ha estado a punto de funcionar. El deficit de la balanza comercial durante el año ha sido de $2.332,8$ millones de dólares (163.293 millones de pesetas), y el indice de cobertura no ha descendido en un 4, pero si en un 3,5 por 100.

A primera vista pudiera parecer que el problema más importante con el que se enfrenta en estos momentos la economia española es el que se deriva de las tendencias registradas en el comercio exterior. Porque téngase en cuenta que, si nos fijamos en la evolución de otras magnitudes, en 1969 se ha logrado lo no experimentado en ningún otro de los años de la década del 60: un aumento notablemente superior al previsto en el II Plan de Desarrollo y, lo que tal vez es más importante, un incremento logrado en la práctica estabilidad de los precios.

De ahí que descubramos el coste de ese crecimiento saneado en las cuentas de nuestro comercio exterior: importaciones que se han situado en la cifra récord de $4.232,9$ millones de dólares, frente a unas exportaciones de sólo 1.900,1 millones de la misma divisa americana.

Analizando un poco más detenidamente las partidas de nuestros intercam. bios con el extranjero, encontramos lo siguiente:

1. El aumento de las importaciones ha sido de un 20,1 por 100 respecto del año anterior; el de las exportaciones de un 19,5 por 100. Como se ve, porcentajes de aumento similares, pero que en la práctica no son significativos; en efecto, la base de cálculo del porcentaje es más del doble cuando se trata de las importaciones. Ese 20,1 por 100 supone, asi, 49.759 millones de pesetas, rrente a sólo 21.768 millones que representa el 19.5 por 100 de las exportaciones.

2. El capitulo más voluminoso de nuestras compras en el extetior se re. flere a la maquinaria: 59.577 millones de pesetas, frente a 13.026 de venta de maquinaria española.

3. A la maquinaria siguen en importancia los productos minerales-sobre todo el petróleo-, con 45.570 millones de pesetas de compra, frente a 11.639 de venta. Es de observar que es ésta la única partida en la que la exportación absoluta disminuyó respecto del año anterior (en 308 millones de pesetas). 
4. Los productos vegetales ocupan tradicionalmente el primer puesto entre las exportaciones, con un volumen para 1969 de 22.773 millones de pesetas. pero es lamentabje comprobar también un déficit en este renglón de productos derivados de la agricultura; las importaciones aloanzaron efectivamente una cifra de 26.321 millones de pesetas.

5. Las exportaciones de material de transporte se sitúan en un volumen de 10.095 millones de pesesas $y$, por orden de importancia, ocupan el quinto puesto en el gráfico de partidas exportadas. Está integrado este apartado en gran medida por la exportación de buques.

Creemos que estos pocos datos globales se prestan a dateminadas con sideraciones de interés.

Comprobamos, en primer lugar, que el déficit de nuestra balanza comercial o de mercancias es creciente a lo largo de los áttimos años. En el último, este déficit no ha sido suficientemente compensado por los ingresos por turismo y remesas de emigrantes; no lo ha sido, puesto que, como to hemos visto, se ha producido un verdadero drenaje de divisas en 1969. Es preciso, pues, invertir la tendencia. Pero icómo?

Un primer camino es el de seguir una política especifica de fomento a las exportaciones y freno a las importaciones. A tal finalidad apuntan los cré ditos, desgravaciones fiscales y primas a la exportación, asi como el depósito previo a las importaciones.

Pero nos parece mucho más importante la reforma estructural del propio sistema interior productivo y la atención a su coyuntura. Porque, como decia García Moncó, si tuviésemos una siderurgia suficientemente grande y com petitiva, la importación de productos siderúrgicos sería menor. $Y$ esto ayudaría a conseguir un menor déficit comercial.

Y si las explotaciones ganaderas fuesen más concentradas, se podría producir más carne en condiciones más competitivas. Las importaciones quedarian asi reducidas.

Si los estímulos a la producción de cereales fuesen diferentes, se podrian reducir los excedentes de trigo o cebada y aumentar la producción de maiz. $Y$ las importaciones, verdaderamente onerosas, de este cereal disminumian.

Si la industria textll fuese menos atomizada, las condiciones de costo mejorarian, las importaciones podrian reduetrse lbremente y las exportaciones aumentar.

En definitiva, problemas más importantes que los especificos de exportan ción e importación son los de dimensión, de productividad, de adecuación de las producciones a la demanda, etc., que acaban mantiestandose en el déficit comercial.

Otro tanto se diga de los aspectos coyunturales. Poco menos que inútiles serán los esfuerzos por dar ánirnos a la exportación si en el interior se desencadena un proceso inflacionista. Los empresarios renunciarfan a mucho del esfuerzo exportador atraidos por el señuelo del crecimento de los precios 


\section{J. GOROSOUIETA}

interiores. Y las importaciones acudirian también al mismo reclamo de los prectos.

Oueremos con esto decir que el comercio exterior es un verdadero espejo del propio sistema económico. Fomentemos exportaciones y frenemos importaciones no reproductivas, pero cambiemos sobre todo nuestro sistema en su estructura para que su magen en la balanza de mercancias aparezca verdaderamențte transformada. 